\title{
A COMPARATIVE STUDY BETWEEN OXYTOCIN INTRAVENOUS BOLUS VERSUS OXYTOCIN INTRAVENOUS BOLUS AND INFUSION FOR CONTROL OF BLOOD LOSS AT ELECTIVE CESAREAN SECTION
}

\author{
By \\ Mohammed M. Mahmoud, Ismail El-Garhey and Adel A. El-Boghdady \\ Department of Obstetrics and Gynecology, Faculty of Medicine, Al-Azhar University \\ Corresponding author: Mohammed M. Mahmoud;
}

Mobile: 0114170 4171, E-mail: abohamzarooka@gmail.com

\begin{abstract}
Background: Postpartum hemorrhage following vaginal birth or cesarean section birth and constitute a serious health problem and are associated with increased risk of maternal morbidity and mortality. Almost all of these maternal deaths could be avoided if complications are diagnosed early and treated appropriately.

Objective: To assess the value of additional oxytocin infusion and bolus versus bolus only in control of blood loss during cesarean section and its role in prevention of major obstetric hemorrhage.

Patients and Methods: In this study, 200 pregnant females at 38-40 weeks gestation were recruited from AlHussein and Sayed Galal hospital, Al-Azhar University Maternity hospitals (Patients admitted for elective cesarean section). Routine full blood count was performed before operation on admission and 48 hours after delivery to assess hemoglobin and hematocrit.

Results: As regards patients received oxytocin bolus only; it was found that a significantly higher prevalence of patient receiving additional uterotonics in this group in comparison to patient receiving oxytocin bolus and oxytocin infusion. As regards occurrence of major obstetric hemorrage we found no change in patient receiving oxytocin bolus only and patient receiving bolus and oxytocin infusion showed no significant difference between both groups as regards patient developed side effects. Also, no significant difference as regards patient developed severe anemia.
\end{abstract}

Conclusion: additional oxytocin infusion (40 IU oxytocin in $500 \mathrm{~mL}$ of saline solution over the next four hours at a rate of $125 \mathrm{~mL}$ ) after $5 \mathrm{~mL}$ i.v. oxytocin infusion at elective cesarean section may reduce need of additional uterotonics.

Key words: Oxytocin, intravenous, infusion, blood loss elective Cesarean section.

\section{INTRODUCTION}

Cesarean delivery is defined as the birth of a fetus through incision in the abdominal wall (laparotomy) and the uterine wall (hysterotomy). This definition does not include removal of the fetus from the abdominal cavity in case of rupture uterus or in the case of an abdominal pregnancy (Sung and Mahdy, 2019).

Cesarean section rates had increased steadily in both developed and developing countries beyond recommended percentages by World Health Organization (10-15\%) (ACOG, 2019). 


\section{MOHAMMED M. MAHMOUD et al.,}

Although cesarean delivery greatly improves obstetric outcomes when clinically indicated, excessively high Cesarean delivery rates have raised concern about the health and economic consequences of this practice (Magne et al., 2017). In China, it approaches $46 \%$ in 2011. In Egypt it reaches $29.5 \%$ in 2011 (Kirchengast and Hartmann, 2019).

The rising rates of primary cesarean sections have resulted in a large population with scarred uteri and in subsequent pregnancies these women are risk-prone (Elebrashy et al., 2011).

Major obstetric hemorrhage (more than $35 \%$ blood loss) continued to be one of the most common cause of direct maternal death (more than half of cases of maternal death) in obstetric practice (Shivakumar et al., 2013).

The management of bleeding in cesarean section is a shared responsibility between obstetricians and anesthetists, Different figures varying from less than $500 \mathrm{ml}$ to more than $1000 \mathrm{ml}$ have been quoted as estimation of blood loss associated with cesarean section. There is also a wide variation in blood ordering practices for this surgery. Several factors like habit, training and medico-legal concerns may be responsible in addition to difficulty in blood loss assessment in Cesarean sections (Aksoy et al., 2015).

The use of an uterotonic drug immediately after the birth of the newborn is one of the most important actions used to prevent postpartum hemorrhage (PPH). Many considerations are selecting these uterotonic agents as cost, Efficacy, stability, response time, adverse effects, contraindications, requirements for administering the drug (Gallos et al., 2018).

The golden point when using oxytocin or any other uterotonic drug is to obtain satisfactory uterine tone by least amount to reduce side effects of the uterotonic agents (hypotension, nausea, emesis) and to reduce time for establishment and maintenance of adequate uterine tone (Vallera et al., 2017).

Oxytocin is the most common uterotonic drug used to control, prevent and treat postpartum hemorrhage (PPH). The value of routine oxytocics in the third stage of vaginal birth has been well established and it has been assumed that these benefits apply to cesarean delivery as well. Royal College of Obstetrics and Gynecology (RCOG, 2014) recommend a slow i.v bolus dose of oxytocin following delivery of the baby at cesarean section. Some clinicians use an additional infusion of oxytocin for a further period following the procedure. Intravenous oxytocin has a very short half-life (4-10 minutes) therefore the potential advantage of an oxytocin infusion is that it maintains uterine contractility throughout the surgical procedure and immediate postpartum period, when most primary hemorrhages occur (Güngördük et al., 2018).

Use of lowest effective dose of oxytocin may decrease side effects. The bolus dose of oxytocin used at elective cesarean deliveries in non-laboring women can be significantly reduced while maintaining effective uterine contraction. Alteration in practice will likely reduce the potential adverse effects of this drug when given in large bolus doses, but may require modification of the techniques to 
remove the placenta (Bhattacharya et al., 2013).

The aim of this study was to compare the intravenous slow bolus of oxytocin versus the intravenous slow bolus of oxytocin and oxytocin infusion on control of blood loss at elective cesarean section.

\section{PATIENTS AND METHODS}

Two hundred healthy women were recruited from the outpatient clinic in AlHussein and Sayed Galal hospitals, AlAzhar University. The patients will be admitted in the inpatient ward of both hospitals for elective ceaserean section. All females included in the study gave written consents after explanation of the nature of the study.

The study included women with singleton pregnancies, aged $>17$ years, with gestational age ranging from 38-40 weeks calculated from the first day of the last normal menstrual period and no medical complications (cardiac, renal, hypertensive, diabetic disorders).

Women with previous major obstetric hemorrhage, patients at risk of postpartum hemorrhage (PPH): Previous history of PPH, Placenta praevia/acreta (history of antepartum hemorrhage), oversized uterus e.g twin pregnancy, polyhydramnious, uterine fibroid and bleeding tendency e.g (anticoagulant therapy, idiopathic and thrombocytopenic purpura (ITP), women with more than previous three cesarean sections, intervention that lengthen the operation e.g ovarian cystectomy, incisional hernia repair and tubal ligation, trial of labor and preterm labor were excluded from the study.
The females subjected to this study were divided into the following equal groups: Group (A) received an intravenous slow bolus of oxytocin $5 \mathrm{IU}$ and a placebo infusion $(0.9 \%$ saline solution $500 \mathrm{ml}$ over 4 hours),and Group (B) received oxytocin bolus $5 \mathrm{IU}$ and oxytocin infusion (40 units in $500 \mathrm{ml}$ $0.9 \%$ saline over 4 hours).

All females in the study were subjected to detailed history taking to obtain data regarding patients age, parity and number of previous cesarean section, general examination, ante-natal investigations (Rh, complete blood picture, PT, PTT, INR and PC), fasting and postprandial blood sugar and complete urine analysis), full blood count 48 hours after delivery to assess hemoglobin and hematocrit, developing of severe anemia >20 \% reduction in $\mathrm{Hb}$.

Cases were followed after delivery, stay in theatre and recovery room to ensure continuity of infusion, and to detect uterine atony, development of early lochial loss, postpartum hemorrhage and any side effects of oxytocin, serial clinical examination, blood pressure and pulse measurements.

Oxytocin bolus $5 \mathrm{IU}$ and oxytocin infusion (40 IU oxytocin in $500 \mathrm{~mL}$ saline infused over four hours) were compared with 5 IU oxytocin bolus and placebo infusion $(500 \mathrm{~mL}$ saline infused over 4 hours).

Randomisation took place after patients consented to participation in the study. We used an automated web based randomization system ensuring allocation concealment. Allocation was stratified by centre and previous cesarean section (no/yes), and blocked by use of random 
permuted blocks of varying size. We randomly assigned women to receive either an intravenous slow bolus of oxytocin 5 IU over 1 minute and 40 IU oxytocin in $500 \mathrm{~mL}$ of $0.9 \%$ saline solution over 4 hours (bolus and infusion), or an oxytocin bolus 5 IU over 1 minute and $500 \mathrm{~mL}$ of $0.9 \%$ saline solution over 4 hours $(2.5 \mathrm{ml} / \mathrm{min}$ bolus only).

Anesthesia was standardized. An intravenous bolus of $500 \mathrm{ml}$ crystalloid was given to all patients prior to spinal anesthesia. Intravenous crystalloids were continued at 1 liter every 8 hours until the morning after surgery, unless the patient was unable to tolerate oral fluids.

Surgical approach to cesarean section was standardized. Surgeons were asked to operate to a standard procedure that specifies controlled cord traction for delivery of the placenta after administration of the oxytocin bolus, two layer closure of the uterine incision, and to avoid delivering the uterus for suturing unless clinically indicated.

An objective measure of blood loss was calculated using pre- and postoperative hematocrit (EBL cal Calculated estimated blood loss). The estimate was calculated as follows:

\author{
EBL $=($ EBV $x$ (Pre-op Hct - Post-op \\ Het)) / Pre-op Het
}

\section{Where EBV estimated blood volume = Booking weight in $\mathrm{kg} \mathrm{x} 85$.}

Blood loss at operation was replaced with colloid infusion or blood. Postoperative pain relief consisted of regular non-steroidal analgesia combined with paracetamol. Vital signs were monitored. Clinical follow-up of the mother was completed prior to hospital discharge.

Study protocol was submitted for approval by the Ethical Committee of faculty of Medicine, AL-Azhar University.

\section{Statistical analysis:}

Recorded data were analyzed using the statistical package for the social sciences, version 20.0 (SPSS Inc., Chicago, Illinois, USA). Quantitative data were expressed as range, mean \pm standard deviation (SD). Qualitative data were expressed as frequency and percentage. The following tests were done: Mann- Whitney U test was used when comparing between two means. Chi-square (x2) test of significance was used in order to compare proportions between qualitative parameters. The confidence interval was set to $95 \%$ and the margin of error accepted was set to $5 \%$. So, the p-value $<0.05$ was considered significant.

\section{RESULTS}

Two patients had blood transfusion in group (A) and 8 developed severe anemia 6 patients in group (A) and one patient in group (B), 34 patients need Additional uterotonic 22 patients in group (A) and 12 patients in group (B) Demographic and clinical characteristics of the studied groups: the mean age of group (A) was 31.63 years and group (B) was 30.97.

No statistically significant difference was found between groups according to their baseline characteristics regarding 
age, GA, number previous CS and parity, with p-value $>0.05$ (Table 1).

Table (1): Comparison between group $A$ and group $B$ according to baseline characteristics $(n=200)$

\begin{tabular}{|c|c|c|c|}
\hline $\begin{array}{ll}\begin{array}{l}\text { Baseline } \\
\text { characteristics }\end{array} & \text { Groups }\end{array}$ & $\begin{array}{c}\text { Group A } \\
(\mathbf{n}=\mathbf{1 0 0})\end{array}$ & $\begin{array}{c}\text { Group B } \\
(\mathbf{n}=\mathbf{1 0 0})\end{array}$ & p-value \\
\hline \multicolumn{4}{|l|}{ Age (vears) } \\
\hline Range & $19-43$ & $18-45$ & \multirow{2}{*}{$>0.05$} \\
\hline Mean \pm SD & $31.63 \pm 7.55$ & $30.97 \pm 7.79$ & \\
\hline \multicolumn{4}{|l|}{ GA (wks) } \\
\hline Range & $38-41$ & $38-41$ & \multirow{2}{*}{$>0.05$} \\
\hline Mean \pm SD & $38.44 \pm 1.04$ & $38.48 \pm 0.89$ & \\
\hline \multicolumn{4}{|l|}{ Number Previous CS } \\
\hline Range & $0-3$ & $0-3$ & \multirow{2}{*}{$>0.05$} \\
\hline Mean \pm SD & $0.79 \pm 1.05$ & $1.05 \pm 1.03$ & \\
\hline \multicolumn{4}{|l|}{ Parity } \\
\hline$\geq 2$ & $52(52 \%)$ & $56(56 \%)$ & \multirow{2}{*}{$>0.05$} \\
\hline$<2$ & $48(48 \%)$ & $44(44 \%)$ & \\
\hline
\end{tabular}

No statistically significant difference between groups according to their adherence to surgical protocol and adherence to anesthetic protocol, with pvalue >0.05. The study revealed no statistically significant difference between groups according to previous pelvic surgery, with p-value $>0.05$. A statistically significant difference was found between groups regarding add. Uterotonics, there were 22 cases Yes $(22.9 \%)$ and 74 cases male $(77.1 \%)$ of group A, also were 12 cases Yes $(12.2 \%)$ and 86 cases No $(87.8 \%)$ of group B regarding Add. Uterotonics, with p-value $<0.05$ (Table 2).

Table (2): Comparison between group $A$ and group $B$ according to adherence to surgical protocol and adherence to anathetic protocol, previous pelvic surgery and add. uterotonics $(n=200)$.

\begin{tabular}{|c|c|c|c|}
\hline Parameters $\quad$ Groups & $\begin{array}{c}\text { Group A } \\
(\mathbf{n}=100)\end{array}$ & $\begin{array}{c}\text { Group B } \\
(\mathbf{n}=100)\end{array}$ & p-value \\
\hline \multicolumn{4}{|l|}{ Adherence to surgical protocol } \\
\hline Yes & $88(88 \%)$ & $92(92 \%)$ & \multirow{2}{*}{$>0.05$} \\
\hline No & $12(12 \%)$ & $8(8 \%)$ & \\
\hline \multicolumn{4}{|l|}{ Adherence to anesthetic protocol } \\
\hline Yes & $96(96 \%)$ & $88(88 \%)$ & \multirow{2}{*}{$\mathbf{0 . 0 3 7}$} \\
\hline No & $4(4 \%)$ & $12(12 \%)$ & \\
\hline \multicolumn{4}{|l|}{ Previous pelvic surgery } \\
\hline Yes & $8(8 \%)$ & $10(10 \%)$ & \multirow{2}{*}{$>0.05$} \\
\hline No & $92(92 \%)$ & $90(90 \%)$ & \\
\hline \multicolumn{4}{|l|}{ Add. Uterotonics } \\
\hline Yes & $22(22.9 \%)$ & $12(12.2 \%)$ & \multirow{2}{*}{$>0.05$} \\
\hline No & $74(77.1 \%)$ & $86(87.8 \%)$ & \\
\hline
\end{tabular}


The study showed no statistically significant difference between groups according to estimated blood loss and hemorrhage, with p-value $>0.05$. There was no statistically significant difference between groups according to their mean of $\mathrm{Hb}$. pre-operative in group A $10.88 \pm 0.97$ compared to group B $11.13 \pm 1.17$, with pvalue $>0.05$. While no statistically significant difference between groups according to their mean of $\mathrm{Hb}$. post- operative in group A $10.22 \pm 1.08$ compared to group B $10.60 \pm 1.20$, with pvalue $>0.05$. Also no statistically significant difference between groups according to their difference in pre and post-operative by $\mathrm{Hb}$. in group $\mathrm{A}$ $0.66 \pm 0.25$ compared to group $\mathrm{B}$ $0.53 \pm 0.16$, with $\mathrm{p}$-value $>0.05$. There was no statistically significant difference between groups according to their severe anemia, with p-value $>0.05$ (Table 3).

Table (3): Comparison between group $A$ and group $B$ according to estimated blood loss, hemorrhage, hematocrit and severe anemia $(n=200)$

\begin{tabular}{|c|c|c|c|}
\hline $\begin{array}{ll}\text { Parameters } & \text { Groups } \\
\end{array}$ & $\begin{array}{c}\text { Group A } \\
(\mathbf{n}=100)\end{array}$ & $\begin{array}{c}\text { Group B } \\
(\mathbf{n}=\mathbf{1 0 0})\end{array}$ & p-value \\
\hline Estimated blood loss & $840.65 \pm 397.56$ & $547.51 \pm 222.15$ & $>0.05$ \\
\hline \multicolumn{4}{|l|}{ Hemorrhage } \\
\hline$>1000$ & $16(16.7 \%)$ & $6(6.1 \%)$ & \multirow{2}{*}{$>0.026$} \\
\hline$<1000$ & $80(83.3 \%)$ & $92(93.9 \%)$ & \\
\hline \multicolumn{4}{|l|}{ Preoperative $(n=200)$} \\
\hline Range & $8.08-13.13$ & $7.98-13.86$ & \multirow{2}{*}{$>0.05$} \\
\hline Mean \pm SD & $10.88 \pm 0.97$ & $11.13 \pm 1.17$ & \\
\hline \multicolumn{4}{|l|}{ Post-operative (n=194) } \\
\hline Range & $6.84-12.92$ & $7.51-13.23$ & \multirow{2}{*}{$>0.05$} \\
\hline Mean \pm SD & $10.22 \pm 1.08$ & $10.60 \pm 1.20$ & \\
\hline $\begin{array}{l}\text { Difference in maternal pre } \\
\text { and post-operative }\end{array}$ & $0.66 \pm 0.25$ & $0.53 \pm 0.16$ & $>0.05$ \\
\hline \multicolumn{4}{|l|}{ Severe anemia } \\
\hline$>20 \%$ & $8(8.3 \%)$ & $2(2.0 \%)$ & \multirow{2}{*}{0.047} \\
\hline$<20 \%$ & $88(91.7 \%)$ & $96(98.0 \%)$ & \\
\hline
\end{tabular}

There was no statistically significant difference between groups according to their shows side effects of oxytocin, with p-value $>0.05$. There was no statistically significant difference between groups according to their mean of postnatal length of stay in (theatre) in group A $45.84 \pm 17.06$ compared to group B
$44.74 \pm 9.64$, with p-value $>0.05$. While no statistically significant difference between groups according to their mean of postnatal length of stay in recovery room in group A $16.48 \pm 6.15$ compared to group B 15.45 \pm 5.63 , with p-value $>0.05$ (Table 4). 
Table 4): Comparison between group $A$ and group $B$ according to shows side effects of oxytocin, postnatal length of stay in theater and postnatal length of stay in recovery room

\begin{tabular}{|l|c|c|c|}
\hline $\begin{array}{l}\text { Shows side effects of } \\
\text { oxytocin }\end{array}$ & $\begin{array}{c}\text { Group A } \\
(\mathbf{n = 9 6})\end{array}$ & $\begin{array}{c}\text { Group B } \\
(\mathbf{n = 9 8})\end{array}$ & p-value \\
\hline No & $76(79.2 \%)$ & $78(79.6 \%)$ & 0.631 \\
\hline Hypotension & $6(6.3 \%)$ & $8(8.2 \%)$ & 0.139 \\
\hline Nausea & $6(6.3 \%)$ & $6(6.1 \%)$ & 0.751 \\
\hline Vomiting & $8(8.3 \%)$ & $6(6.1 \%)$ & 0.572 \\
\hline $\begin{array}{l}\text { Postnatal length of stay in } \\
\text { (theatre) }\end{array}$ & $45.84 \pm 17.06$ & $44.74 \pm 9.64$ & 0.449 \\
\hline $\begin{array}{l}\text { Postnatal length of stay in } \\
\text { recovery room }\end{array}$ & $16.48 \pm 6.15$ & $15.45 \pm 5.63$ & 0.530 \\
\hline
\end{tabular}

\section{DISCUSSION}

In many countries, cesarean section $(\mathrm{C} / \mathrm{S})$ has become the mode of delivery in over a quarter of all births. It is the most commonly performed operation in obstetrics (Singh et al., 2018).

In this study, we choose to follow the recommendation in 2004 of Royal College of Obstetricians and Gynaecologists (RCOG, 2014). Guideline on cesarean section recommends a slow intravenous bolus dose of $5 \mathrm{IU}$ of oxytocin following delivery of the infant.

We debated the choice of primary outcome and decided on two outcomes, both reflecting uterine atony. Major obstetric hemorrhage is the most relevant clinical outcome because it is a leading cause of maternal death worldwide.

We measured total blood loss at the time of cesarean section but chose a calculation based estimate, based on preoperative and postoperative packed cell volume as a primary outcome in the interests of objectivity. The measured blood loss would be more relevant in resource poor settings where blood tests are not routinely performed.
In this study, the mean age of group A was 29.48 years and group B was 28.86. The difference was statistically insignificant. Also, there was insignificant difference between both groups as regarding maternal weight, gestational age (GA).

Our results showed no significant difference in both group as regarding number of previous cesarean section. This result was in accordance with the study done by Gungorduk and Colleagues (2010).

The difference was statistically insignificant between both groups as regarding vascularity of lower segment, adherence to surgical protocol, adherence to anesthetic protocol, parity $\geq 2$, history of previous pelvic surgery. This indicates that both groups were almost identical statistically and gave statistical value to our results. This result was in accordance with the initial large study by Sheehan and Colleagues (2011).

Results of the current study showed higher need for additional utrotonics in group A compared to group B. The difference was statistically significant. 
Similar to our results, were obtained by Sheehan et al. (2011).

Also, Güngördük et al. (2010) found that there were more women in the placebo group who needed additional uterotonic agents than in the oxytocin group, and this difference was statistically significant.

However, unlike to our results, King et al. (2010), in a small trial, investigated the effects of a placebo bolus and oxytocin infusion compared with an oxytocin bolus and oxytocin infusion, and found no difference in the need for an additional uterotonic agent in the first 24 hours after cesarean section.

Comparison between group A and group B regarding estimated blood loss mean value during cesarean section was statistically insignificant. Similar to our results, Sheehan et al. (2011) compared the effects of a 5-IU oxytocin bolus and placebo infusion versus a 5-IU oxytocin bolus and $40 \mathrm{IU}$ infusion and found that no statistical difference between both group as regarding mean blood loss (587 $\mathrm{ml})$ compared to $(583 \mathrm{ml})$.

Unlike our results, Güngördük et al. (2010) found that mean blood loss after 5 IU oxytocin and 30 IU oxytocin in 500 $\mathrm{mL}$ of lactated Ringer's solution administration was less than after 5 IU oxytocin and $500 \mathrm{~mL}$ of lactated Ringer's solution administration. However, different methods of estimating blood loss limits direct comparison with other studies.

Our results showed no statistical difference between both groups as regarding occurrence of major obstetric hemorrhage $>1000 \mathrm{ml}$. Similar to our results, Sheehan et al. (2011) found no difference in the occurrence of major obstetric hemorrhage between the groups. They reported that women were less likely to have a major obstetric hemorrhage in the bolus and infusion group than in the bolus only group if the obstetrician was junior rather than senior.

Unlike our results, Güngördük et al. (2010) found that after 5 IU oxytocin and 30 IU oxytocin in $500 \mathrm{~mL}$ of lactated Ringer's solution administration, the percentage of patients with blood loss $>1000 \mathrm{~mL}$ and required blood transfusion were less with infusion group.

Owonikoko et al. (2011), compared the effectiveness of oral misoprostol and intravenous oxytocin in reducing blood loss in women undergoing indicated or elective cesarean delivery under spinal anesthesia, in prospective, double-blind pilot study. They stated that oxytocin followed by oral misoprostol is as effective as an oxytocin injection followed by an oxytocin infusion in reducing postoperative blood loss after cesarean delivery, and the protocol may be a safe, valuable, and cost-effective alternative to oxytocin alone. Visual estimation of intraoperative blood loss undervalues the effective value of misoprostol use was by $30 \%$.

The golden point when using oxytocin or any other uterotonic drug is to obtain satisfactory uterine tone by least amount to reduce side effects of the uterotonic agents (hypotension, nausea, emesis), and to reduce time for establishment and maintenance of adequate uterine tone (Yamaguchi et al., 2016).

There was a statistical insignificance between both groups regarding numbers 
of cases develop side effects (SE) of uterotonics drugs. The results in this study showed use of oxytocin infusion after an initial bolus did not increase the occurrence of side effects of oxytocin (hypotension, nausea and vomitting). Our results showed patients developed hypotension (3/48) in bolus only group comparing to (4/49) in bolus and infusion group. Patients developed nausea (3/48) in bolus only group comparing to (3/49) in bolus and infusion group. Patients developed vomiting (4/48) in bolus only group comparing to (3/49) in bolus and infusion group this was statistically insignificant. This result was in accordance of Sheehan et al. (2011) where they found no side effects in infusion and bolus group, $20.1 \%$ in bolus and infusion group comparing to $18.0 \%$ in bolus only.

Similar to our results, Güngördük et al. (2010) found no statistical difference in the incidence of utrotonics side effects between the two groups.

There was a statistical insignificance between both groups regarding difference in maternal pre and post-operative hematocrit (drop in hematocrit) mean value. Similar to our results, Sheehan et al. (2011) compared the effects of a 5-IU oxytocin bolus and placebo infusion versus a 5-IU oxytocin bolus and $40 \mathrm{IU}$ infusion, and they found no significant difference drop in hematocrit. Unlike our results, Güngördük et al. (2010) found a statistically significant lower postoperative hematocrit level in placebo group.

There was a statistical insignificance between both groups regarding difference in maternal pre and post-operative $\mathrm{Hb} \%$ (drop in $\mathrm{Hb} \%$ ) mean value.
Unlike our results, Güngördük et al. (2010) found statistically significant lower postoperative hemoglobin level in placebo group.

There was a statistical insignificance between both groups regarding number of cases developed severe anemia. Like our result, Sheehan et al. (2011) found no significant difference between both groups as regard number of patients developed severe anemia.

There was a statistical insignificance between both groups regarding postnatal length of stay in theatre and recovery room respectively. Like our result, Sheehan et al. (2011) found no significant different between both groups as regarding postnatal length of stay in theatre and recovery room respectively.

Butwick et al. (2015) agreed that the initial period after placental delivery during CS is important in terms of bleeding risk. Early assessment and confirmation of adequate uterine tone is vital in potentially reducing the risk of post-partum hemorrhage. As a result, they set a primary time point for assessment at 2 min after oxytocin injection. The use of low doses of oxytocin as an infusion may result in a significant time-delay in achieving the initial uterotonic effect, as the half-life of oxytocin is 5-12 $\mathrm{min}$ and metabolic clearance rates are high leading to higher postnatal hospital stay.

Unlike our results, Güngördük et al. (2010) found that mean length of hospital stay was longer in the placebo group than in the oxytocin group, which was also statistically significant. 


\section{MOHAMMED M. MAHMOUD et al.,}

\section{CONCLUSION}

Additional oxytocin infusion (40 IU oxytocin in $500 \mathrm{~mL}$ of saline solution over the next four hours at a rate of $125 \mathrm{~mL} /$ ) after $5 \mathrm{~mL}$ i.v. oxytocin infusion at elective cesarean section may reduce need of additional uterotonics.

\section{REFERENCES}

1. Aksoy H, Aksoy Ü, Yücel B, Özyurt SS, Açmaz G, Babayiğit MA, Gökahmetoğlu G and Aydın T. (2015): Blood loss in elective cesarean section: is there a difference related to the type of anesthesia? A randomized prospective study. Journal of the Turkish German Gynecological Association, 16(3):158-214.

2. American College of Obstetricians and Gynecologists' Committee on Practice Bulletins Obstetrics (2019): ACOG Practice Bulletin No. 205: Vaginal Birth after Cesarean Delivery. Obstet Gynecol., 133(2):e110-e127.

3. Bhattacharya S, Ghosh S, Ray D, Mallik $S$ and Laha A. (2013): Oxytocin administration during cesarean delivery: Randomized controlled trial to compare intravenous bolus with intravenous infusion regimen. Journal of Anesthesiology, Clinical Pharmacology, 29(1):32-38

4. Butwick AJ, Carvalho B, Blumenfeld YJ, El-Sayed YY, Nelson LM and Bateman BT. (2015): Second-line uterotonics and the risk of hemorrhagerelated morbidity. Am J Obstet Gynecol., 212:642 e641-647.

5. Elebrashy AE, Kassab $A$ and Nada A. (2011): Role of oxytocin in management of third stage at elective cesarean section. Kasr Alainy Journal of gynecology and obstetrics, 2(1): 216-221.

6. Gallos I, Williams H, Price M, Pickering K, Merriel A, Tobias A, Lissauer D, Gee
H, Tunçalp Ö, Gyte G and Moorthy V. (2018): Uterotonic drugs to prevent postpartum hemorrhage: a network metaanalysis. Obstet Gynecol, 211-219.

7. Güngördük K, Asicioglu O, Celikkol O, Olgac Y and Ark C. (2010): Use of additional oxytocin to reduce blood loss at elective cesarean section: a randomised control trial. Australian and New Zealand Journal of Obstetrics and Gynaecology., 50(1):36-9.

8. Güngördük K, Olgaç Y, Gülseren V and Kocaer M. (2018): Active management of the third stage of labor: A brief overview of key issues. Turkish Journal of Obstetrics and Gynecology, 15(3):188-256.

9. King KJ, Douglas MJ, Unger W, Wong A and King RA. (2010): Five unit bolus oxytocin at cesarean delivery in women at risk of atony: a randomized, double-blind, controlled trial. Anesth Analg, 111: 14606.

10.Kirchengast $S$ and Hartmann B. (2019): Recent lifestyle parameters are associated with increasing cesarean section rates among singleton term births in Austria. International Journal of Environmental Research and Public Health, 16(1):14-19.

11.Magne F, Puchi Silva A, Carvajal B and Gotteland M. (2017): The elevated rate of cesarean section and its contribution to non-communicable chronic diseases in Latin America: the growing involvement of the microbiota. Frontiers in pediatrics., 5:192-314.

12.Owonikoko KM, Arowojolu AO, Okunlola MA. (2011): Effect of sublingual misoprostol versus intravenous oxytocin on reducing blood loss at cesarean section in Nigeria: a randomized controlled trial. Journal of Obstetrics and Gynaecology Research. 37(7):715-21.

13.Royal College of Obstetricians and Gynaecologists (ROCG) (2014): Clinical 


\section{A COMPARATIVE STUDY BETWEEN OXYTOCIN INTRAVENOUS...}

Effectiveness Support Unit. National Sentinel Cesarean Section. Audit Report, 201-203.

14.Sheehan SR, Montgomery AA, Carey M, McAuliffe FM, Eogan M, Gleeson R, Geary $M$ and Murphy DJ. (2011): Oxytocin bolus versus oxytocin bolus and infusion for control of blood loss at elective cesarean section: double blind, placebo controlled, randomised trial. BMJ, 343-355.

15.Shivakumar HC, Umashankar KM, Ramaraju HE and Shankar J. (2013): Analysis of maternal mortality in tertiary care hospital, vijaya nagara institute of medical sciences, Bellary, South India. Int J Basic Appl Medn Sci., 3(2):237-42.

16.Singh P, Hashmi $G$ and Swain PK. (2018): High prevalence of cesarean section births in private sector health facilities-analysis of district level household survey-4 (DLHS-4) of India. BMC Public Health, 18(1):613.

17.Sung $S$ and Mahdy H. (2019): Cesarean Section. [Updated 2020 Aug 23]. In: Stat Pearls [Internet] pbl. Treasure Island (FL): Stat Pearls Publishing, P. 218-233.

\section{Vallera C, Choi LO, Cha CM and Hong} RW. (2017): Uterotonic medications: oxytocin, methylergonovine, carboprost, misoprostol. Anesthesiology Clinics.,35 (2):207-19.

19.Yamaguchi ET, Siaulys MM and Torres ML. (2016): Oxytocin in cesareansections. What's new? Revista brasileira de anesthesiology, 66(4):402-7. 
در اسة مقارنة للحقن الوريدى للأوكسيتوسين مقابل الحقن

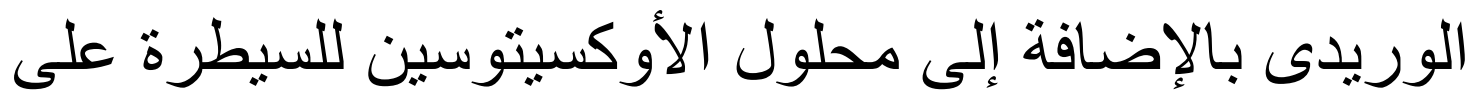

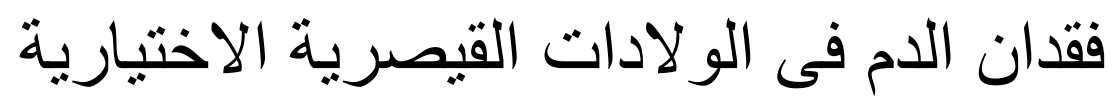

محمد محمود السيا محمود، إسماعيل طلعت الجارحي، عادل علي البغدادي

قسم التوليد وأمراض النساء، كلية الطب، جامعة الأزهر

E-mail: abohamzarooka@gmail.com

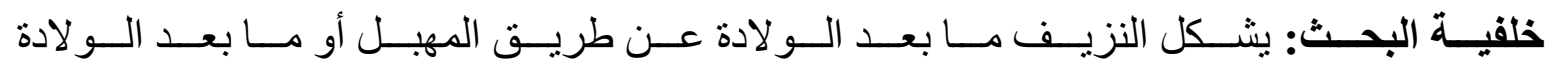

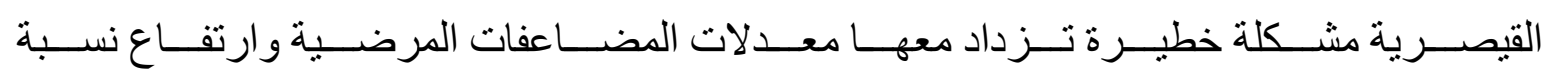

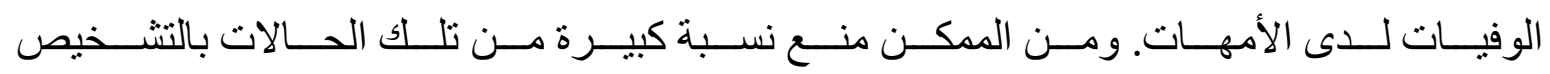

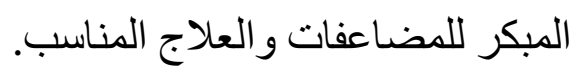

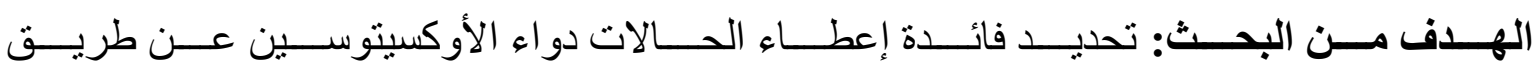

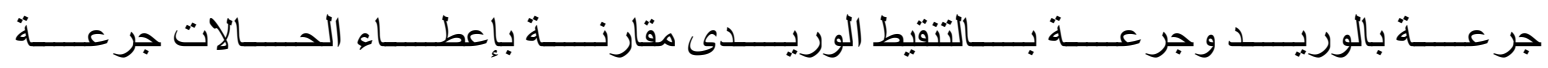

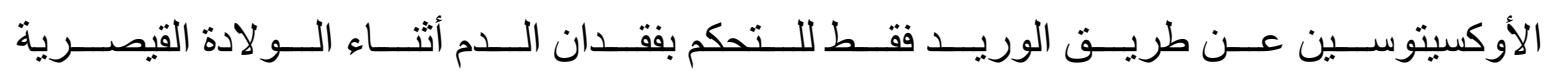

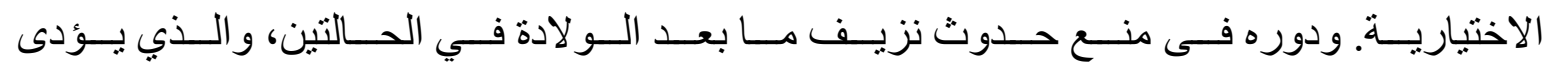

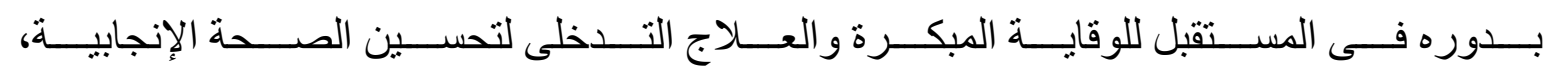

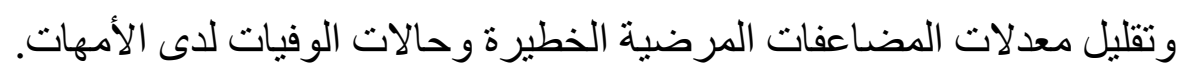

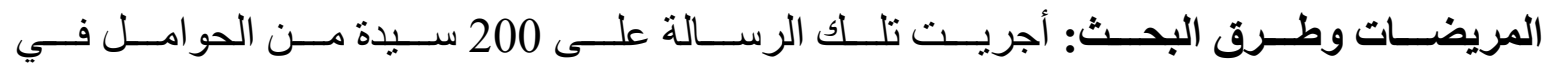

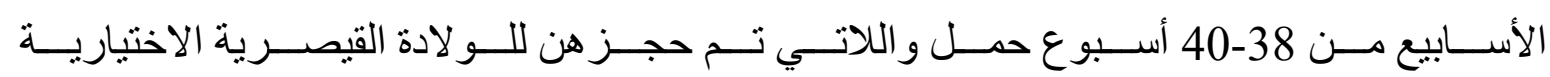

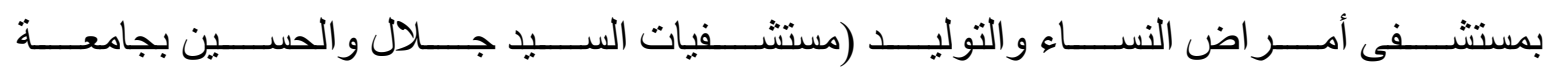

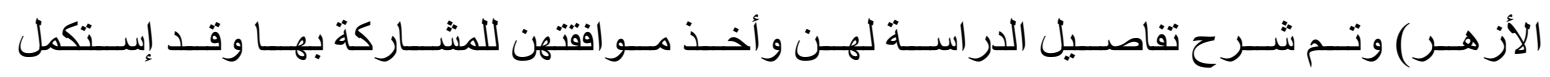
المتابعة 194 سيدة فقط حتى الو لادة.

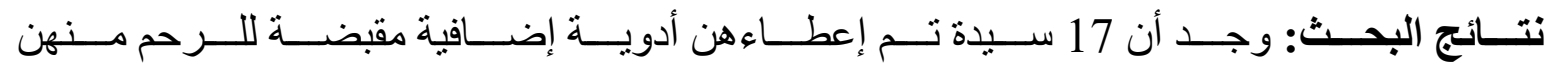

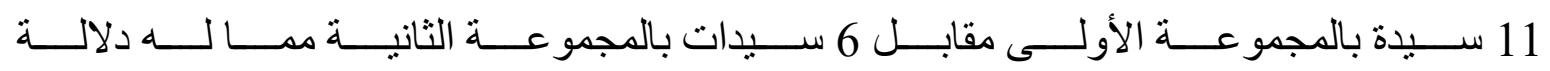

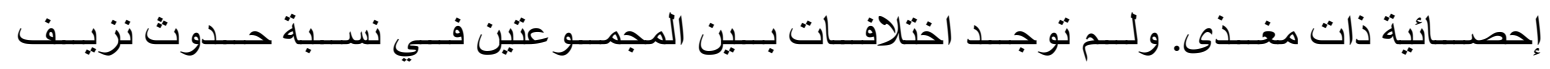

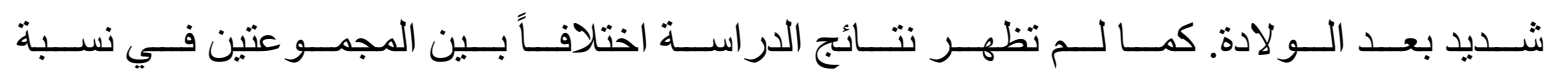


A COMPARATIVE STUDY BETWEEN OXYTOCIN INTRAVENOUS...

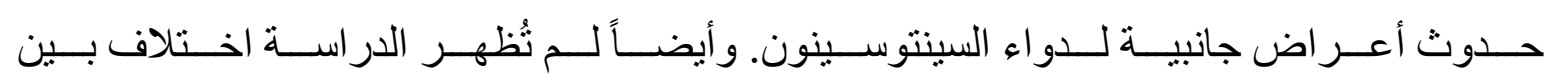
المجمو عتين من حيث حدوث أنيميا حادة (فقر بالدم).

الاســـتتاج: إضــــافة الأوكسيتوســين (بجرعـــة 40 وحـــدة دوليـــة مــن الأوكسيتوســين فــي

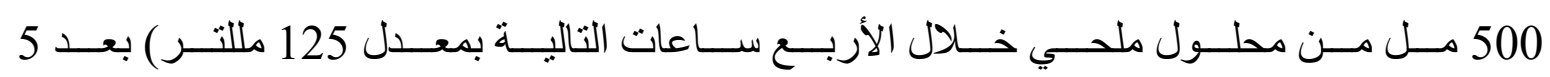

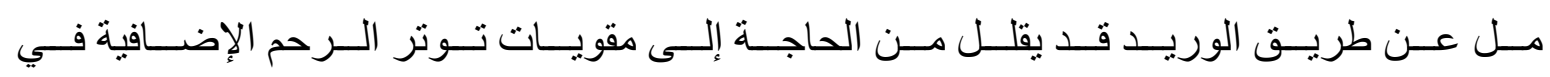
حالات الو لادة القيصرية الاختيارية.

الكلمات الدالة : أكسيتوسيني - الحقن الوريدى ـ فقد الدم - القيصرية . 